INPLASY

PROTOCOL

To cite: Shao. The comparison of percutaneous ethanol and polidocanol sclerotherap for Cystic Kidney Disease:a systematic review and metaanalysis. Inplasy protocol 202220064. doi: 10.37766/inplasy2022.2.0064

Received: 16 February 2022

Published: 16 February 2022

Corresponding author: Changfu Shao

2694194988@qq.com

Author Affiliation:

jose

Support: Changfu Shao.

Review Stage at time of this submission: The review has not yet started.

Conflicts of interest:

None declared.

\section{The comparison of percutaneous ethanol and polidocanol sclerotherapy for Cystic Kidney Disease: a systematic review and meta-analysis}

Shao, C1.

Review question / Objective: To compare the difference and efficacy between ethanol and polidocanol in treatment of Cystic Kidney Disease.

Condition being studied: The sclerotherapy agent for Cystic Kidney Disease is controversial.

Information sources: Pubmed, embase, cochrane library, CNKI, wanfang data.

INPLASY registration number: This protocol was registered with the International Platform of Registered Systematic Review and Meta-Analysis Protocols (INPLASY) on 16 February 2022 and was last updated on 16 February 2022 (registration number INPLASY202220064).

\section{INTRODUCTION}

Review question / Objective: To compare the difference and efficacy between ethanol and polidocanol in treatment of Cystic Kidney Disease.

Condition being studied: The sclerotherapy agent for Cystic Kidney Disease is controversial.

\section{METHODS}

Participant or population: Patients with Cystic Kidney Disease.

Intervention: Polidocanol sclerotherapy.

Comparator: Ethanol sclerotherapy.

Study designs to be included: Chinese and english study. 
Eligibility criteria: No recurrence, reduced size of cysts.

Information sources: pubmed, embase, cochrane library, CNKI, wanfang data.

Main outcome(s): No recurrence, reduced size of cysts.

Quality assessment / Risk of bias analysis: Cochrane List.

Strategy of data synthesis: Stata or review manager.

Subgroup analysis: Country, race, dose, size of renal cyst and so on.

Sensitivity analysis: Funnel plot, Subgroup analysis.

Language: Chinese and english.

Country(ies) involved: China.

Keywords: Kidney Diseases, Cystic Punctures drainage Sclerotherapy.

Contributions of each author:

Author 1 - Changfu Shao.

Email: 2694194988@qq.com 